\title{
DIRECTIONAL PREFERENCES OF THE CHIFFCHAFF (Phylloscopus collybita) AND THE ROBIN (Erithacus rubecula) ON AUTUMN MIGRATION IN THE BESKID NISKI MOUNTAINS (S POLAND)
}

\author{
Karolina Adamska and Monika Filar
}

\begin{abstract}
Adamska K., Filar M. 2005. Directional preferences of the Chiffchaff (Phylloscopus collybita) and the Robin (Erithacus rubecula) on autumn migration in the Beskid Niski Mountains (S Poland). Ring 27, 2: 159-176.

Data were collected at the "Akcja Carpatica" ringing station in the southern Poland in 2000-2003. In total 388 Robins and 357 Chiffchaffs were tested with the Busse's method (Busse 1995) for directional preferences during autumn migration. The data were elaborated using a non-standard calculation procedure proposed by Busse and Trocińska (1999) that could be applied to multimodal circular distributions.

Tested birds showed $\mathrm{ca}$ 69\% (the Chiffchaff) and more than $60 \%$ (the Robin) of northern headings that we called "reversed directions" for autumn migration. We applied "reversing procedure", i.e. adding $180^{\circ}$ to all northern directions. Such procedure was based on an assumption that birds show axial behaviour in the cage.

The species seasonal catching dynamics was divided into periods reflecting migration waves. Both studied species showed differentiation of directional preferences. In the Robin such directions as: SSE, SSW, ESE and WSW were noted. Most clear migration pattern was observed for the Chiffchaff - SSE and WSW directions dominated.

Although in both species sampling was short and irregular, the Chiffchaff migration pattern was clear and similar in all studied seasons. On the contrary, the Robin showed complicated and difficult to analyse headings' distributions. Robins indicated both intra- and interseasonal differentiation of directional preferences.
\end{abstract}

K. Adamska and M. Filar, Bird Migration Research Station, University of Gdańsk, Przebendowo, PL-84-210 Choczewo, Poland.

Publication appointed to the SE European Bird Migration Networks papers

Key words: cage experiments, autumn migration, directional preferences, Phylloscopus collybita, Erithacus rubecula 


\section{INTRODUCTION}

Bird migration has fascinated many researchers for a very long time. First individuals were ringed in 1899, while in 1950 first complex theory on bird navigation during migration was developed (Wiltschko and Wiltschko 2001).

Birds during migration are exposed to different environmental factors, like weather, stopover quality, predators (Lindström et al. 1996). To conduct comprehensive studies on migration we have to include migration strategy, population differentiation, migration directions, bird physiological condition (Busse 1992) into our analyses.

Nowadays, our knowledge on bird migration is based mainly on the studies that included visual observations, bird ringing and consequent recovery analysis, biometrical analysis, etc. However, still a kind of mystery are bird orientation and navigation mechanisms. Studies on this topic have included highly specialised research methods. Nowadays, the most common are: telemetry, radar studies and cage experiments. The first one - telemetry - is based on satellite tracking that is a very expensive method, moreover due to the transmitters weight, or rather both weight and life of the batteries cannot be used in the studies on passerines. The second one - radar tracking - registers bird migration as radar echoes. This method, however, is unreliable in identification of similar-size species. Moreover, only large flocks can be registered, what means that individual birds are not included, particularly of small species (Nowakowski and Malecka 1999). The third one - cage experiments is based on registration of migratory restlessness and is used in studies on bird orientation and navigation abilities. First experiments of such kind were conducted by Kramer (1949) and Sauer (1957). This method, however, could not be implemented in the field conditions. The simple type of orientation cage was designed by Emlen and Emlen (1966). In this funnel cage a tested individual jumped on the sloping walls covered with paper. There was an ink pad on the cage bottom, so the birds left the footprints on the wall. This method, although commonly used in laboratory experiments (e.g. Wiltschko and Wiltschko 1978, Weindler 1997, Weindler et al. 1998) was rarely used in the field conditions (e.g. Rabøl 1985). The method was criticised as a highly stressing situation to the tested migrants (e.g. Gerrard 1981). In 1995, Busse designed a new type of an experimental cage, as well as he proposed to test the birds immediately after they were caught, instead of keeping them till night, as it was done before - all these decrease influence of stress on tested individuals (Busse 1995). This method was used to test typical night migrants (e.g. Nowakowski and Malecka 1999, Trocińska et al. 2001, Busse et al. 2001, Formella and Busse 2002, Ściborska and Busse 2004).

In this paper we present results of studies on typical night migrants: the Chiffchaff and the Robin. Autumn migration of the Robin lasts from September till the end of October. Northern and Central European populations migrate to wintering grounds located in west and south Europe, Northern Africa and Asia Minor 
(Cramp 1988). Most of European Chiffchaff's populations are migratory, at least partially. Some birds breeding in north-western part of Europe can winter in Great Britain and Ireland. Most birds of western populations winter to the south of their breeding grounds: in Mediterranean region $-29-45^{\circ} \mathrm{N}$ (Hedenström and Pettersson $1987)$ and in northern Africa. Northern and eastern populations are obligatory migrants that winter in the eastern Africa up to northern India (Hagemeijer and Blair 1997). Autumn migration of this species lasts from September till the beginning of October.

The aim of this study was to learn of directional preferences of the Robin and Chiffchaff during autumn migration in the central part of the Carpathian Mountains - at the ringing station "Akcja Carpatica" located in the south-eastern Poland.

\section{MATERIAL AND METHODS}

All data were collected at the ringing station "Akcja Carpatica", located close to village Myscowa (49 $\left.32^{\prime} \mathrm{N}, 21^{\circ} 34^{\prime} \mathrm{E}\right)$, Krempna parish, in the central part of the Beskid Niski Mountains in the autumns of 2000-2003. The ringing station is located in the River Wisłoka valley. The studied area is covered mainly by grey willows (Salix cinerea), which makes this location a superb stopover (both resting and foraging) place for migrating. The station is in the vicinity of the Magurski National Park. "Akcja Carpatica" is also a member of the SEEN (SE European Bird Migration Network) - an international umbrella organisation for institutions that study bird migration. One of the aims of this network are studies on directional preferences of birds migrating along the not well-investigated SE flyway.

Migrants were caught with mist-nets, and after standard procedures that included ringing and several measurements, they were tested in the Busse's orientation cage according to a standard method developed by this researcher (Busse 1995, Busse 2000). All tests were conducted during the day-time: 6.00 a.m. -7.00 p.m. and the birds were tested not later than two hours after they had been caught in the nets.

With the use of the ORIENT 4.5 programme (P. Busse, University of Gdańsk), we input and then elaborated collected data. New elaboration procedure proposed by Busse and Trocińska (1999) enables analysis of multimodal circular data distributions. A standard procedure applied to the individual orientation data assumes unimodal bird behaviour, thus individual bird heading is an average of raw data defined by a direction given in degrees $(\alpha)$ and the length of a vector $r$. In the second step - when analysing bird group data - all individual vectors are used to calculate an average group vector. Once again an assumption of the unimodal data distribution is made. In the calculation procedure applied in this study, multimodal distributions well-documented by Busse and Trocińska (1999), Trocińska et al. (2001), Busse et al. (2001) were included, and the group data were given as a sum of individual vectors in the given sectors. 
ORIENT 4.5 programme enabled us to analyse multimodal distributions, i.e. when raw data showed not only one, but also two and more local maxima. Such procedure is based on the observations that many individuals exhibit axial behaviour when tested in the orientation cage (Busse and Trocińska 1999) and on a hypothesis that interpopulational hybrid can have several navigation programmes coded in genes (Busse 1992).

When accepting that tested birds show axial behaviour, one can assume that opposed vectors are of equal biological and logical value, thus can be summed up. To get a migration directional pattern, $180^{\circ}$ was added to all „northern” vectors (i.e. vectors that were opposed to typical autumn migration directions) - this way „reversed” data distributions were obtained. The final results that show directional species preferences are given as the simplified 16-sectors graphs based on a wind-rose. The polygons reflecting relative number of tested birds were used to get a clear picture.

\section{RESULTS}

Autumn passage dynamics graphs of the Chiffchaff and Robin were made for each year separately, based on a number of birds caught every day during the season (Fig. 1 and 2). These graphs enabled us to compare the passage dynamics in dif-
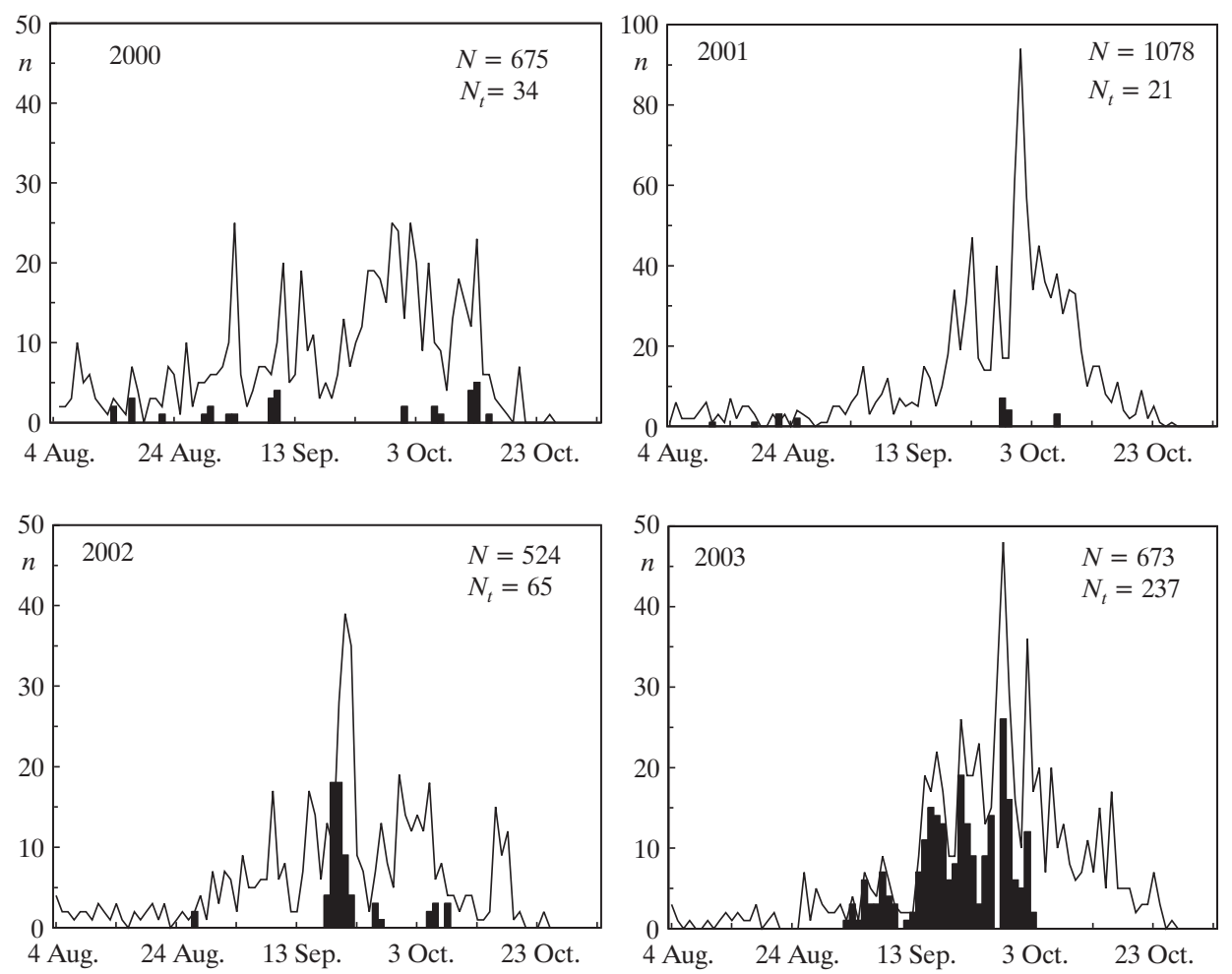

Fig. 1. The Chiffchaff passage dynamics (daily catching number) in 2000-2003. Total number of caught birds $(N$, line $)$ and orientation tests $\left(N_{t}\right.$, bars $)$ are given. 

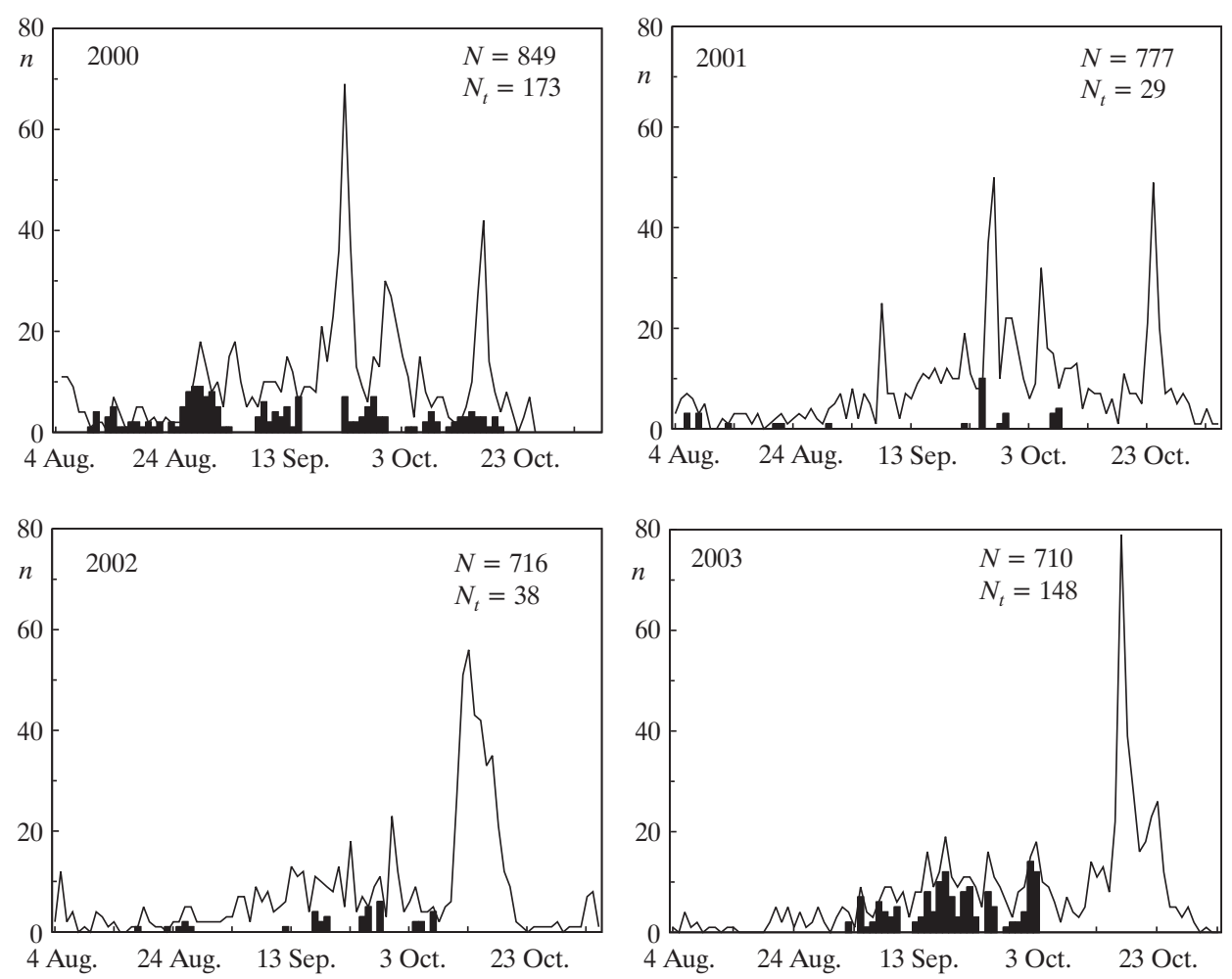

Fig. 2. The Robin passage dynamics (daily catching number) in 2000-2003. Total number of caught birds $\left(N\right.$, line) and orientation tests $\left(N_{t}\right.$, bars) are given.

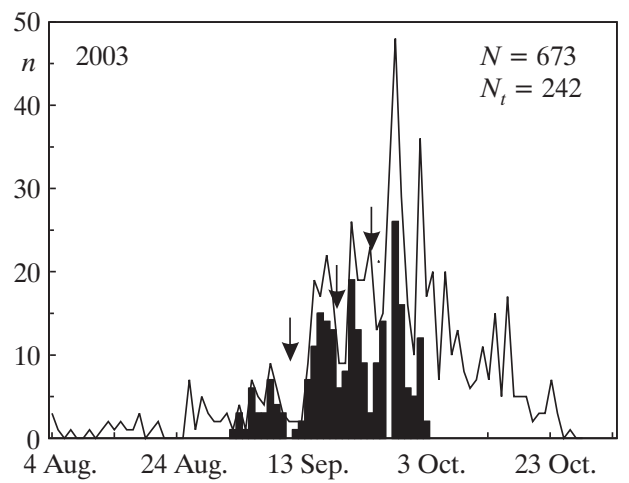

Fig. 3. The Chiffchaff passage dynamics in 2003. Total number of caught birds $(N$, line) and orientation tests $\left(N_{t}\right.$, bars $)$ are given. Arrows point at the borders of analysed periods.

ferent years. Year 2003, analysed in detail, was divided into several periods based on the passage dynamics. Similarly to this procedure also 2000 year (in the case of the Robin) was divided into several periods (Fig. 3 and 4).

In total 745 tests -357 for the Chiffchaff and 388 for the Robin (Table 1 and 2) - done in 2000-2003 were used in this analysis. Only two tested individuals $(0.3 \%)$ 

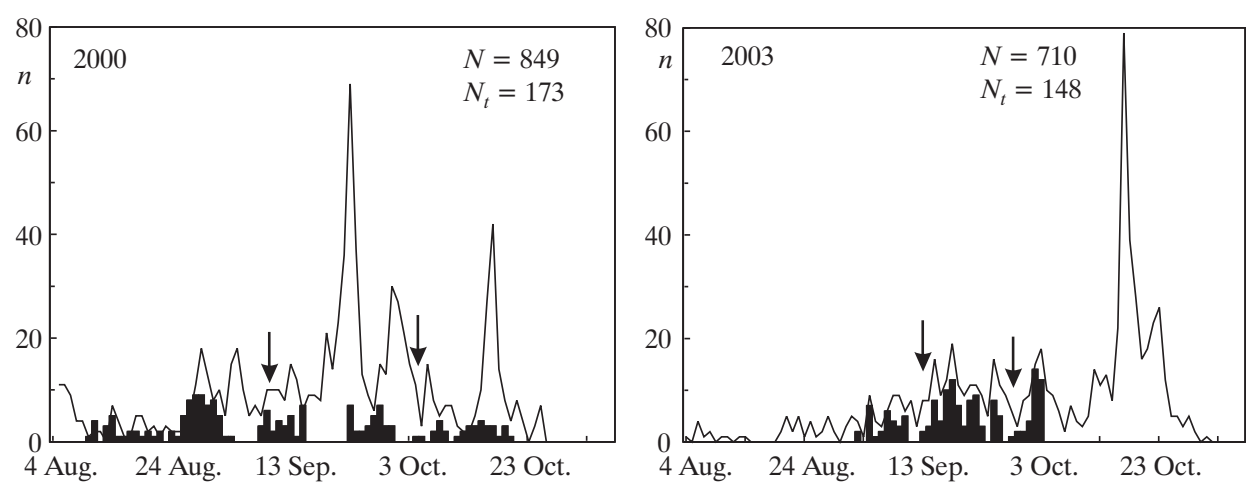

Fig. 4. The Robin passage dynamics in 2000 and 2003. Total number of caught birds $(N$, line) and orientation tests $\left(N_{t}\right.$, bars) are given. Arrows point at the borders of analysed periods.

Table 1

Number of caught and tested Chiffchaffs in 2000-2003

\begin{tabular}{|l|c|c|c|}
\hline & No of caught birds & No of orientation tests & $\begin{array}{c}\text { Proportion of orientation tests } \\
\text { to the number of caught birds (\%) }\end{array}$ \\
\hline 2000 & 675 & 34 & 5 \\
2001 & 1078 & 21 & 2 \\
2002 & 524 & 65 & 12 \\
2003 & 673 & 237 & 35 \\
\hline
\end{tabular}

Table 2

Number of caught and tested Robins in 2000-2003

\begin{tabular}{|l|c|c|c|}
\hline & No of caught birds & No of orientation tests & $\begin{array}{c}\text { Proportion of orientation tests } \\
\text { to the number of caught birds (\%) }\end{array}$ \\
\hline 2000 & 849 & 173 & 20 \\
2001 & 777 & 29 & 4 \\
2002 & 716 & 38 & 5 \\
2003 & 710 & 148 & 21 \\
\hline
\end{tabular}

were categorized as „not active”, i.e. the total number of scratches in one test was less than 20, and were not included in the further analyses. 743 individuals showed clear preferences - data distributions differed significantly from random $\left(\chi^{2}\right.$-test: $p<0.01$ ). Total distributions of the preferred directions are given in Figures 5 and 6.

High proportion of the northern directions observed during autumn migration the Chiffchaff: $74 \%$ in 2000, $73 \%$ in 2001, $64 \%$ in 2002 and $65 \%$ in 2003; and the Robin: $57 \%, 78 \%, 50 \%$ and $56 \%$, respectively (Table 3 and 4 ) - caused us to decide to use only the "reversed" data distributions in the further analyses. Such procedure made analysed material more clear. Moreover, the polygons that represented the local vectors' distributions and number of tested birds were used to ease graphs' interpretation.

The NW direction was a dominating one in the Chiffchaff and was observed in all studied years. It comprised: $53 \%$ in $2000,36 \%$ in $2001,30 \%$ in 2002 and $27 \%$ in 
2000

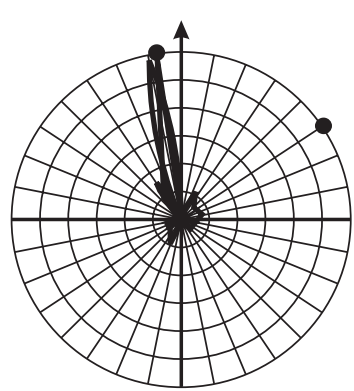

2001

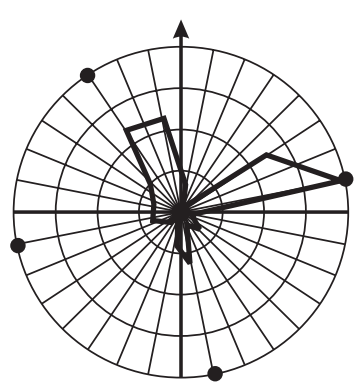

2002

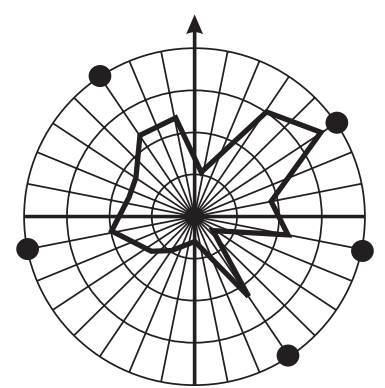

2003

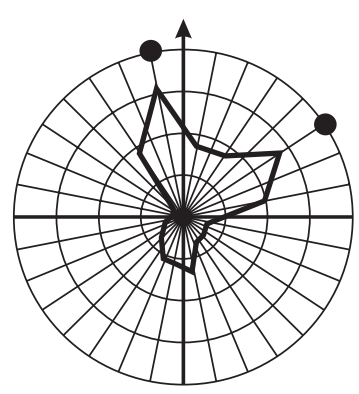

$N=34$

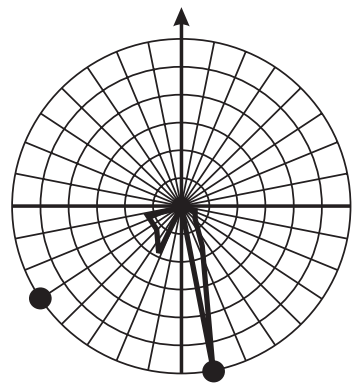

$N=21$

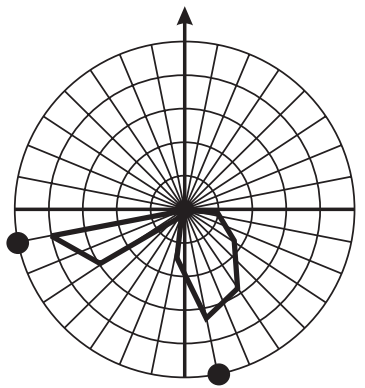

$N=65$

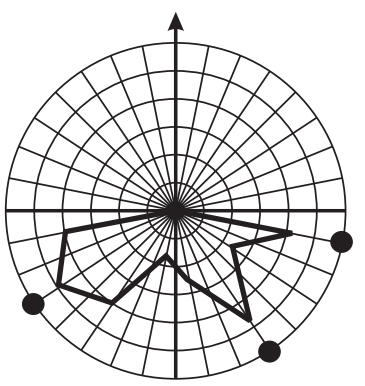

$N=237$

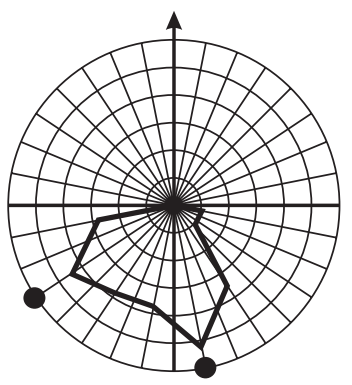

Fig. 5. Distributions of the preferred directions (given in 16 sectors) shown by the Chiffchaff in 2000-2003. Raw data - on the left, reversed data - on the right. Dot - mode value. 

$N=173$
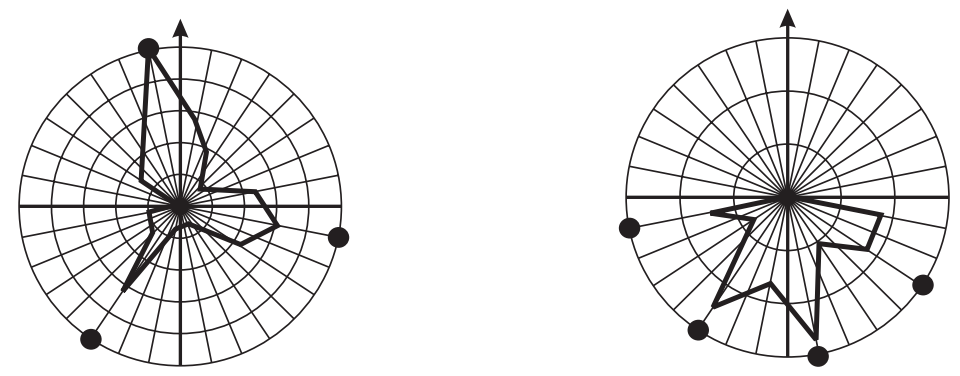

2001

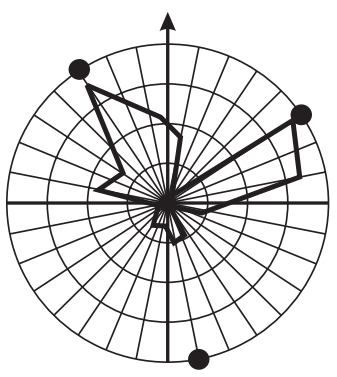

$N=29$

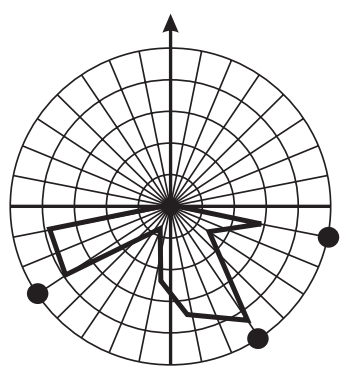

2002

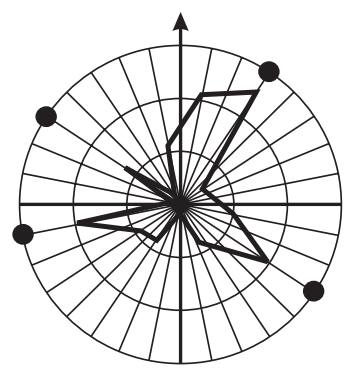

$N=38$

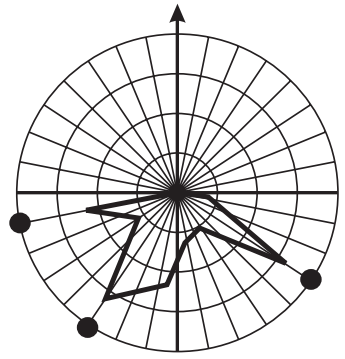

2003
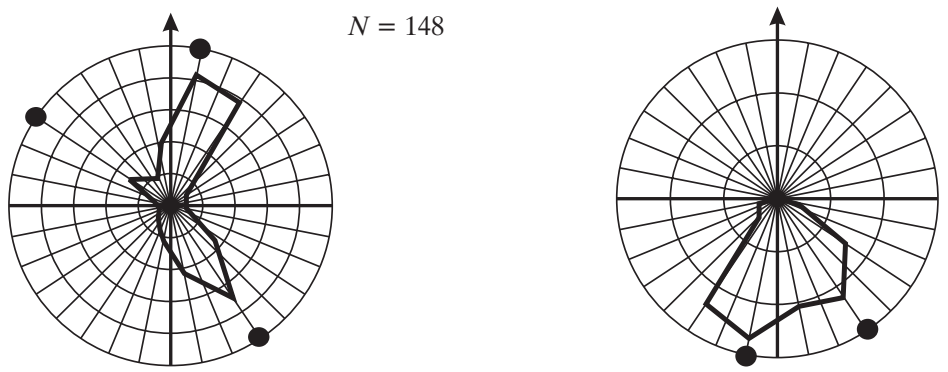

Fig. 6. Distributions of the preferred directions (given in 16 sectors) shown by the Robin in 2000-2003. Raw data - on the left, reversed data - on the right. Dot - mode value. 
Table 3

Migration directions of the Chiffchaff in the studied years (approximate percentage values are given; data for axes NE-SW, NW-SE and azimuths are included)

\begin{tabular}{|c|c|c|c|c|c|c|}
\hline & $\begin{array}{c}\text { Axis } \\
\text { NE-SW }\end{array}$ & $\%$ & Azimuth & $\begin{array}{c}\text { Axis } \\
\text { NW-SE }\end{array}$ & $\%$ & Azimuth \\
\hline \multirow{3}{*}{2000} & $\mathrm{NE}$ & 21 & $53^{\circ}$ & \multirow{2}{*}{$\begin{array}{c}\text { NW } \\
\text { SE }\end{array}$} & \multirow{2}{*}{$\begin{array}{l}53 \\
11 \\
\end{array}$} & $342^{\circ}$ \\
\hline & SW & 17 & $229^{\circ}$ & & & $109^{\circ}$ \\
\hline & $\% \mathrm{NE}$ & 55 & & $\% \mathrm{NW}$ & 83 & \\
\hline \multirow{3}{*}{2001} & $\mathrm{NE}$ & 37 & $63^{\circ}$ & \multirow{2}{*}{$\begin{array}{c}\text { NW } \\
\text { SE }\end{array}$} & \multirow{2}{*}{$\begin{array}{l}36 \\
15 \\
\end{array}$} & $327^{\circ}$ \\
\hline & SW & 12 & $225^{\circ}$ & & & $146^{\circ}$ \\
\hline & $\% \mathrm{NE}$ & 75 & & $\% \mathrm{NW}$ & 71 & \\
\hline \multirow{3}{*}{2002} & $\mathrm{NE}$ & 34 & $47^{\circ}$ & \multirow{2}{*}{$\begin{array}{c}\text { NW } \\
\text { SE }\end{array}$} & \multirow{2}{*}{$\begin{array}{l}30 \\
20 \\
\end{array}$} & $320^{\circ}$ \\
\hline & SW & 18 & $238^{\circ}$ & & & $122^{\circ}$ \\
\hline & $\% \mathrm{NE}$ & 65 & & $\% \mathrm{NW}$ & 60 & \\
\hline \multirow{3}{*}{2003} & $\mathrm{NE}$ & 38 & $47^{\circ}$ & \multirow{2}{*}{$\begin{array}{c}\text { NW } \\
\text { SE }\end{array}$} & \multirow{2}{*}{$\begin{array}{l}27 \\
16 \\
\end{array}$} & $334^{\circ}$ \\
\hline & SW & 19 & $218^{\circ}$ & & & $140^{\circ}$ \\
\hline & $\% \mathrm{NE}$ & 67 & & $\% \mathrm{NW}$ & 63 & \\
\hline
\end{tabular}

Table 4

Migration directions of the Robin in the studied years (approximate percentage values are given; data for axes NE-SW, NW-SE and azimuths are included)

\begin{tabular}{|c|c|c|c|c|c|c|}
\hline & $\begin{array}{c}\text { Axis } \\
\text { NE-SW }\end{array}$ & $\%$ & Azimuth & $\begin{array}{c}\text { Axis } \\
\text { NW-SE }\end{array}$ & $\%$ & Azimuth \\
\hline \multirow{3}{*}{2000} & $\mathrm{NE}$ & 27 & $41^{\circ}$ & \multirow{2}{*}{$\begin{array}{c}\mathrm{NW} \\
\mathrm{SE}\end{array}$} & \multirow{2}{*}{$\begin{array}{l}30 \\
21 \\
\end{array}$} & $334^{\circ}$ \\
\hline & SW & 22 & $226^{\circ}$ & & & $118^{\circ}$ \\
\hline & $\% \mathrm{NE}$ & 55 & & $\% \mathrm{NW}$ & 59 & \\
\hline \multirow{3}{*}{2001} & $\mathrm{NE}$ & 39 & $57^{\circ}$ & \multirow{2}{*}{$\begin{array}{c}\mathrm{NW} \\
\mathrm{SE}\end{array}$} & \multirow{2}{*}{$\begin{array}{l}39 \\
15 \\
\end{array}$} & $320^{\circ}$ \\
\hline & SW & 7 & $221^{\circ}$ & & & $139^{\circ}$ \\
\hline & $\% \mathrm{NE}$ & 85 & & $\% \mathrm{NW}$ & 72 & \\
\hline \multirow{3}{*}{2002} & $\mathrm{NE}$ & 33 & $26^{\circ}$ & \multirow{2}{*}{$\begin{array}{c}\text { NW } \\
\text { SE }\end{array}$} & \multirow{2}{*}{$\begin{array}{l}17 \\
24\end{array}$} & $326^{\circ}$ \\
\hline & SW & 26 & $239^{\circ}$ & & & $124^{\circ}$ \\
\hline & $\% \mathrm{NE}$ & 56 & & $\% \mathrm{NW}$ & 42 & \\
\hline \multirow{3}{*}{2003} & $\mathrm{NE}$ & 36 & $28^{\circ}$ & \multirow{2}{*}{$\begin{array}{c}\text { NW } \\
\text { SE }\end{array}$} & \multirow{2}{*}{$\begin{array}{l}20 \\
32 \\
\end{array}$} & $321^{\circ}$ \\
\hline & SW & 12 & $213^{\circ}$ & & & $145^{\circ}$ \\
\hline & $\% \mathrm{NE}$ & 75 & & $\% \mathrm{NW}$ & 39 & \\
\hline
\end{tabular}

2003. The second direction found in all studied years was NE. In 2000 it was $21 \%$, in $2001-37 \%$, in $2002-34 \%$, and in $2003-38 \%$. In 2001 and 2002 one more direction was observed: SE - it involved $15 \%$ and $20 \%$, respectively. After the "vector reversing" procedure, two main directions found in all studied years were: SSE and WSW. The SSE direction in 2000 comprised 52\%, in $2001-34 \%$, in $2002-26 \%$, and in $2003-32 \%$; the WSW $-22 \%, 41 \%, 31 \%$ and $29 \%$, respectively. In 2002, an additional direction ESE (23\%) was noted. In 2002 the studied period covered al- 
most exclusively the species passage peak. Most probably this was the cause of the direction distributions differences found in that year compared to the pattern shown by the Chiffchaff in other years (Fig. 5).

High differentiation of the analysed distributions in the studied years was observed in the Robin (Fig. 6). In 2000 raw data distributions' analysis showed that dominating direction was NNW (24\%), while ESE (18\%) and SSW (13\%) were also well-represented. After the "reversing procedure" four directions were found: slightly dominating SSW (29\%) and SSE (27\%), as well as clear ESE (24\%) and WSW (20\%). Thus directions' distribution was quite uniform. In 2001 raw data distribution showed two main directions: ENE (31\%) and NNW (25\%). When the reversing procedure was applied following directions were found: SSE (34\%), WSW $(33 \%)$, and the third one not so well-represented was ESE (18\%). In 2002, four directions were found in raw data distribution: dominating NNE (29\%), two almost equal - ESE (18\%) and WSW (19\%) and rather small one - WNW (9\%). Reversed distribution showed SSW (36\%) as a dominating one and two clear directions: ESE $(26 \%)$ and WSW (22\%). In 2003, similarly to the previous year, NNE (31\%) dominated but also a new direction was observed - SSE (22\%). In the reversed distributions two main directions were found: SSW (39\%) and SSE (34\%).

Modal sectors' distributions in the studied years are shown in Figure 7. In the Chiffchaff, the observed pattern is similar in all studied years, it is highly consistent and repeatable (note: modal sectors pointing at SSE and WSW directions). On the contrary, distribution of the preferred directions of the Robin is rather uniform. Only some similarities could be observed in 2000 and 2002, when WSW, SSW and ESE directions dominated. Overall, directions preferred by the tested Chiffchaffs in all four years given as the average azimuths, are as follows: $232^{\circ}-\mathrm{SW}$ sector and $146^{\circ}$ - SE sector (reversed distributions). Directional preferences of the Robins are differentiated - there are four directions observed: SSE, SSW, ESE and WSW, and the average azimuths are $221^{\circ}-\mathrm{SW}$ sector and $139^{\circ}-\mathrm{SE}$ sector. The observed pattern is a complex one and its interpretation is rather difficult. Data described above are given in Figure 8.
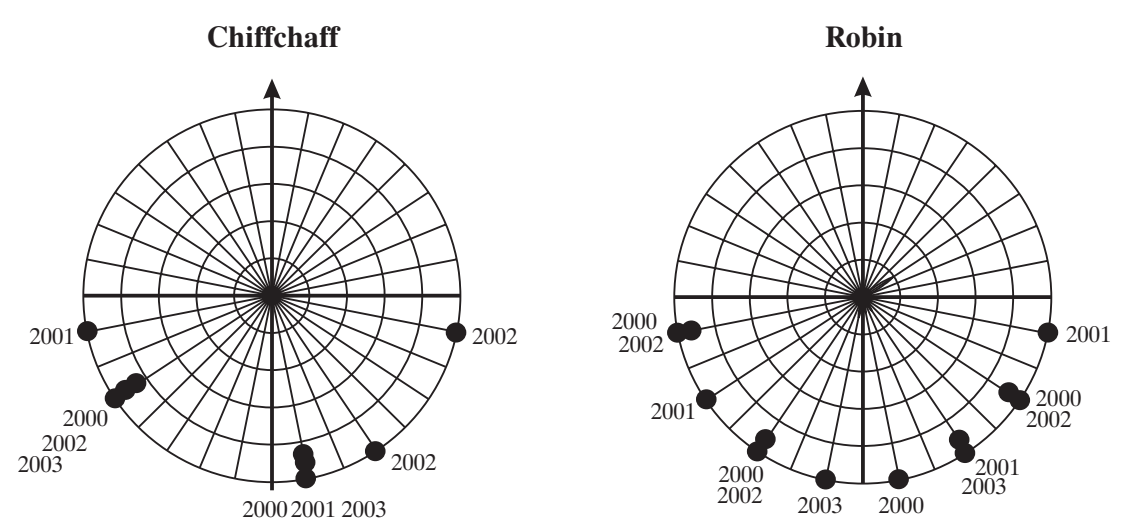

Fig. 7. Summarized distribution of the modal sectors in the studied years in the Chiffchaff (left panel) and the Robin (right panel). 

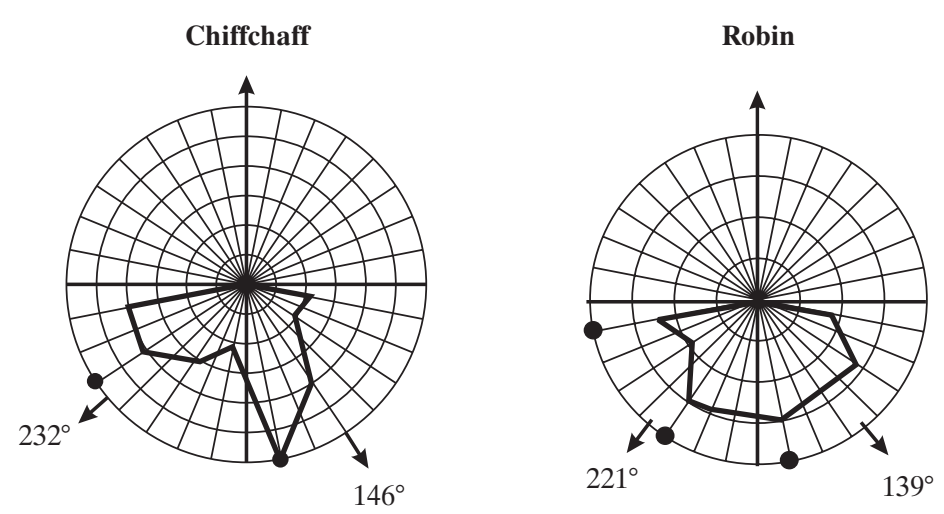

Fig. 8. Summarized distribution of the preferred directions in the Chiffchaff (left panel) and the Robin (right panel) in 2000-2003. Dot - mode value, arrow - average azimuth.

A detailed analysis of the Chiffchaff's directional preferences was based on data from 2003. In that year the highest number of the orientation tests was performed. The species passage that lasted from 4 August to 26 October was divided into four periods (Fig. 3).

In subsequent periods of the Chiffchaff's passage, observed migration directions compared to overall directional pattern did not show much differentiation (Fig. 9). In all described periods Chiffchaffs showed SSE and WSW directions. In the fourth period (IV), ESE direction became clearer. It could be also noted in the first $(I)$ and the third (III) periods as small additional peaks. In the general pattern, in all periods $(I, I I, I I I, I V)$ the values of modal directions fell in the SSE sector and, additionally, in the $I, I I$ and $I I I$ periods another group were values that fell in the WSW sector.

In the Robin, regular sampling that covered whole migration period was available for 2000 and 2003. This enabled us to make similar analysis for these years dividing both of them into three periods (Fig. 4). In the first (I) period of 2000 four directions were observed (Fig. 10, left panel): SSW (slightly dominating), ESE, SSE and WSW, in the second (II) period all these directions were still present but none of them was the dominating one, in the third (III) period there was a clear SSE direction domination, while WSW and ESE directions were quite poorly represented. The analysis of 2003 data showed that in the first $(I)$ period SSW direction was clearly preferred (Fig. 10, right panel). As the time passed, in the second (II) period also SSE direction became clearer. In the last period SSW direction was still the dominating one, but also ESE could be noted. Modal sectors' distributions in the subsequent periods of 2000 and 2003 are shown in Figure 11. Comparison of all modal sectors' distributions for 2000 shows a quite clear picture, only a little bit more differentiated than in the Chiffchaff. In 2003 the pattern shows much higher differentiation of the preferred directions, although some directions were observed in the subsequent periods, i.e. in the $I$ and $I I I-\mathrm{SSW}$, and in the $I$ and $I I-$ SSE. So, it seems 
2-10 Sep. $N=31$

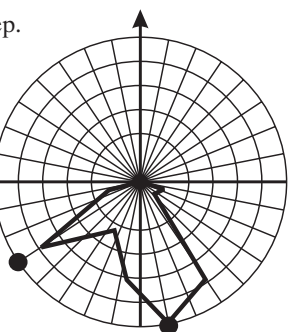

II

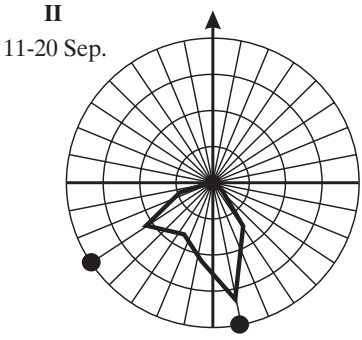

$N=73$

III

7 Sep.

$N=66$
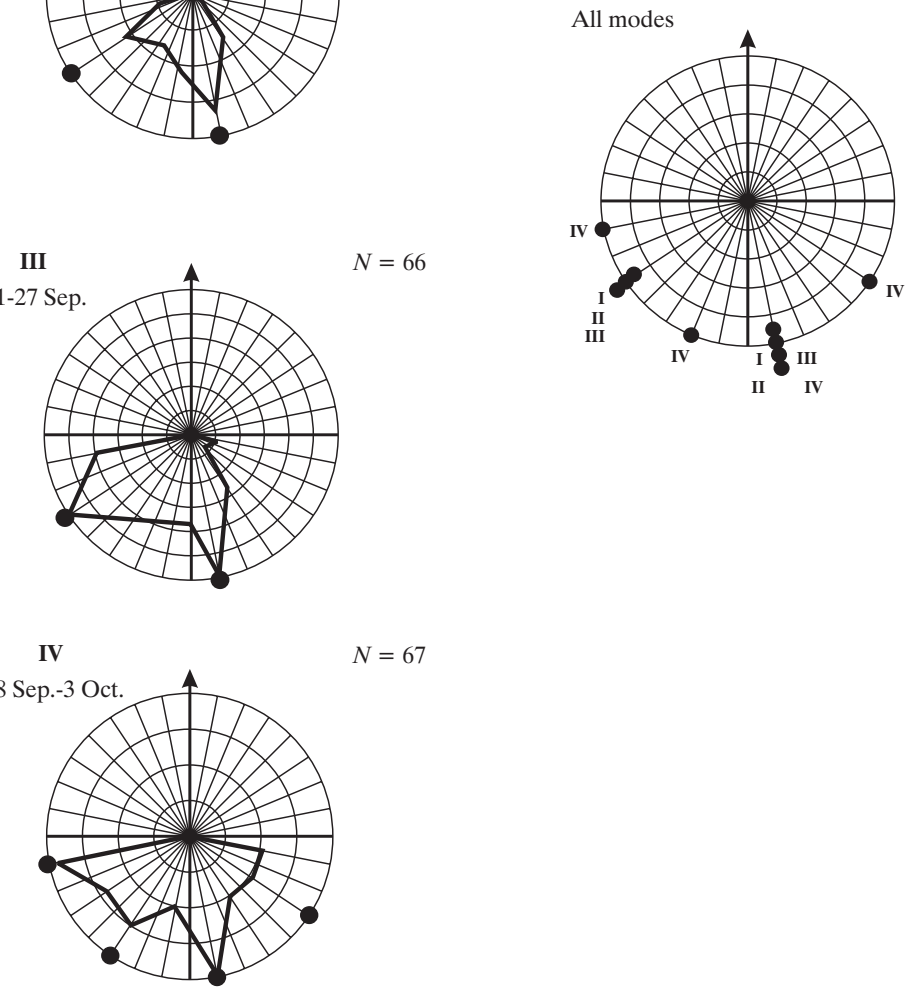

$N=67$

Fig. 9. Distribution of the preferred directions (reversed) in the following periods of 2003 in the Chiffchaff (left panels) and modal sectors' distribution for all periods (right panel). Sample size and local modal sectors are given.

that differetiation of directions within a year is smaller than between various seasons. The causes of this phenomenon should be studied more deeply in further studies. 


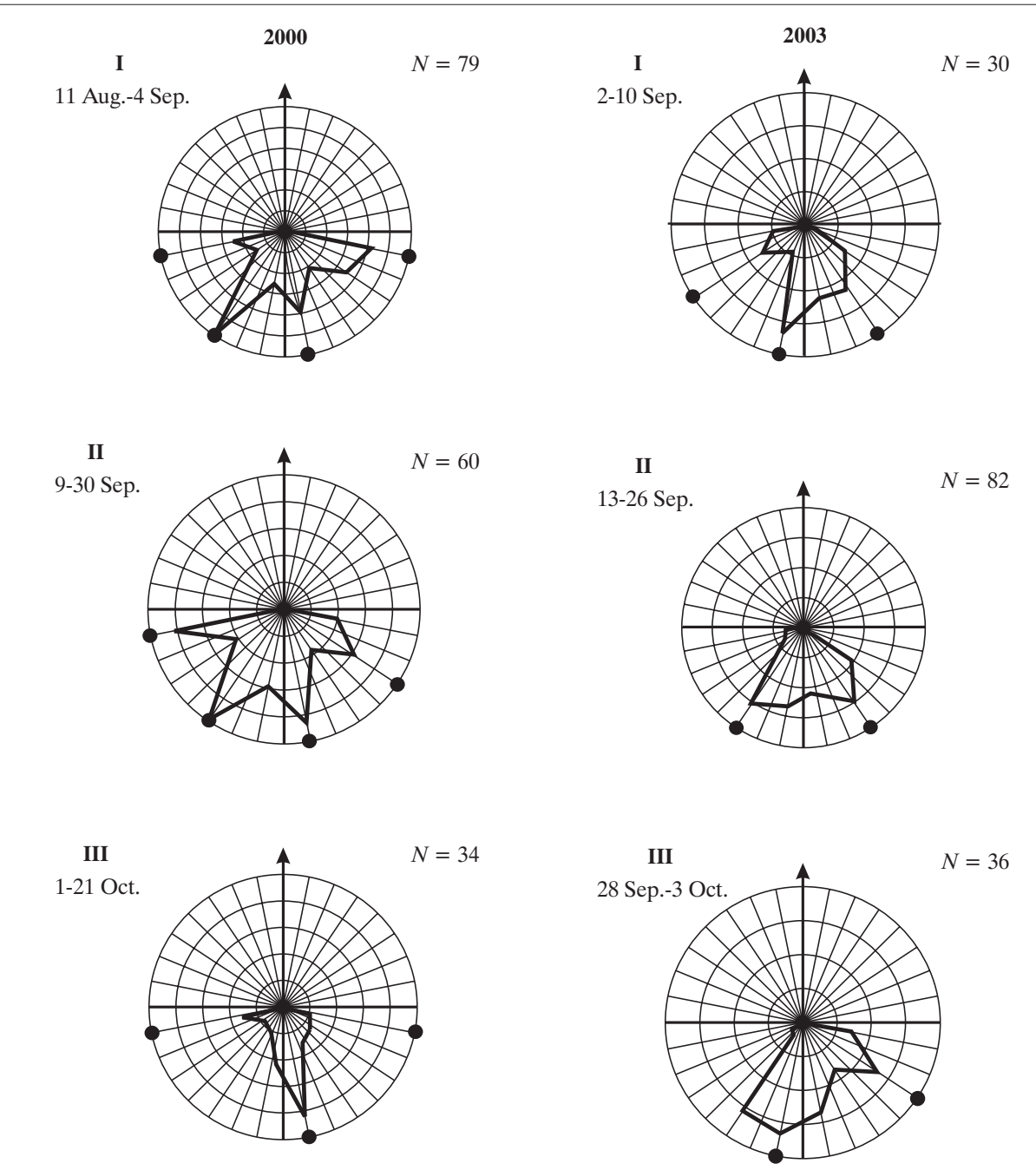

Fig. 10. Distribution of the preferred directions (reversed) in the following periods (of 2000 and 2003) in the Robin. Sample size and local modal sectors are given.
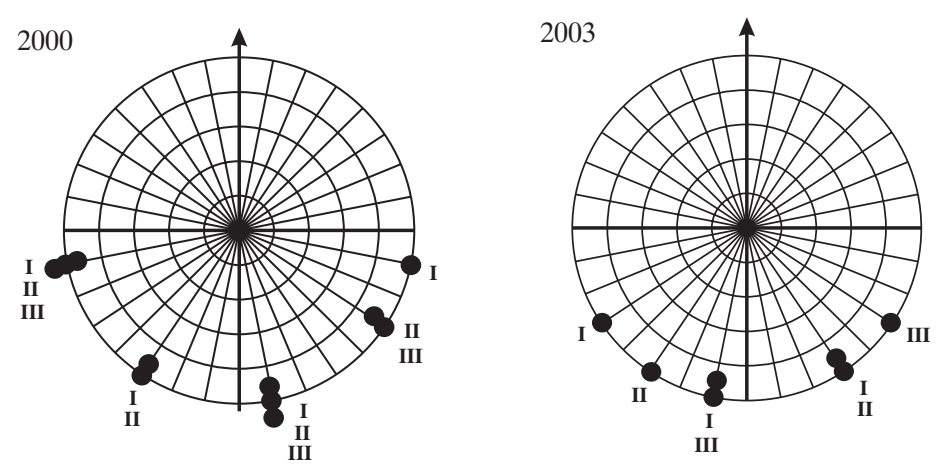

Fig. 11. Modal sectors' distribution in the described periods in the Robin in 2000 and 2003 


\section{DISCUSSION}

Directional preferences analyses of birds tested in the Busse's cage are still quite rare. Nowakowski and Malecka (1999) focused on the analysis of Robins migrating across central part of Poland, while Ściborska and Busse (2004) along the coast. Trocińska et al. (2001) analysed data on the Sedge Warbler (Acrocephalus schoenobaenus) and Reed Warbler (A. scirpaceus) in the central and eastern part of Europe, while Formella and Busse (2002) analysed data on both these species tested in the Drużno Lake Reserve (northern part of Poland). Busse et al. (2001) in their study focused on the Blackcap (Sylvia atricapilla) and Robin tested at several stations in central and western part of Europe. However, there is lack of data on the Chiffchaff directional preferences.

It is quite often observed that directional preferences of birds tested during autumn migration pointed to the northern directions. This phenomenon could be explained by the axial behaviour hypothesis, i.e. that birds have genetically encoded migration direction axiality - directed towards breeding and wintering grounds (Busse 1992). It could happen that a bird, while stressed, would like to leave the cage in the direction that is opposite to the standard one during its autumn migration. Such cases of the reversed migration were observed in natural conditions by Busse (1992) or Remisiewicz and Baumanis (1996). High percentage of northward directions during autumn migration was observed in Robins tested at BukowoKopań station in 1996 - 48.9\% (Busse and Trocińska 1999), as well as in the central part of Poland, where individuals were tested during the day $-20 \%$, and at night 11\% (Nowakowski and Malecka 1999).

Number of Chiffchaffs migrating inland is much higher than that observed along the Baltic Sea coast (Busse and Marova 1993). The Chiffchaff is among dominating species at the ringing station "Akcja Carpatica" located in the Beskid Niski Mountains. If the Busse's method is applied to a group of birds that is large enough and homogenous, then one can expect the observed pattern to be clear. In the Chiffchaff a high number of the tests seemed to be promising but the analysis showed that this number was much differentiated in subsequent years. Sometimes these tests were also unsystematic within a season or, like in 2003, for the season studied in detail with the highest sample sizes available there was lack of data in the final part of passage. In order to get a detailed pattern of the directional preferences it is crucial to study the period that is long enough and not so differentiated, as well as the sampling process has to be well-planned (Busse et al. 2001, Ściborska and Busse 2004). Ideally, one should collect sample size that is proportional to the number of caught birds.

During autumn migration in Myscowa, the Chiffchaff showed two main directions: WSW and SSE, which were observed in all studied years. The WSW direction as a dominating one was also observed by Trocińska et al. (2001) in the Reed Warbler and Sedge Warbler on the east and south Baltic Sea coast. It is also well docu- 
mented in migrating Blackcaps at Bukowo-Kopań ringing station (Busse et al. 2001). The second dominating direction: SSE was earlier observed in the Sedge Warbler by Trocińska et al. (2001) at Cholgyni ringing station in Ukraine.

Seasonal bird migration dynamics was studied by several researchers. Some ornithologists explained the observed bird number fluctuations as a result of environmental conditions (e.g. Lindström et al. 1996) or populational factors (e.g. Busse et al. 2001). If one accepts first assumption then following migration waves should have similar parameters like their size or individuals representing these waves should have similar directional preferences. According to the second one - these waves should be clearly different. While analysing the Chiffchaff migration, the whole passage was divided into periods that generally reflected migration waves. Taking closer look at the pattern observed along two axes: NE-SW and NW-SE (Table 3) some differentiation should be noted. Percentage of preferred directions fluctuated to some degree each year.

The analysis showed that two groups of birds showing similar directional preferences could be observed during the Chiffchaff passage in the studied years - one that most probably goes to the Balkans (SSE) and another showing western wintering grounds in the Mediterranean basin (WSW). One more group directed to the more eastern wintering grounds (ESE) could be observed during the peak of the passage (Fig. 5). This one is clearly shown in 2001 and 2002. Analysis of different periods in 2003 showed that two directions: SSE and WSW could be observed during the whole season, i.e. in periods $I-I V$. During the last one $-I V$, the pattern of directional preferences became complicated. Thus, the beginning of the passage is more homogenous, while during the passage peak some other groups of migrants could also be observed. In subsequent periods some fluctuations in SSE and WSW directions' proportion in overall pattern could be noted.

Robins passing Myscowa could represent different migrational populations. The Operation Baltic studies pointed at the similar conclusion (Remisiewicz 2002, Ściborska and Busse 2004). Birds of each migration wave could represent separate population migrating along different routes to various geographical regions. As a result high differentiation of directional preferences of birds tested at the ringing station could be observed.

Detailed directional preferences analysis for 2000 and 2003, when different passage periods were found according to migration pattern, pointed at changes of directional preferences in subsequent periods (Fig. 10). Similar changes were observed by other researchers (Pettersson and Lindholm 1983, Busse 1986, Formella and Busse 2002, Remisiewicz 2002, Ściborska and Busse 2004). In 2000, in the beginning of migration, during first two periods, both eastern (SSE, ESE) and western directions (SSW, WSW) were present. In the end of the season (October) number of birds showing SSE direction clearly increased. Similar results were found at Swedish ringing station Ottenby (Pettersson and Lindholm 1983) as in October higher number of recoveries from eastern directions were noted. According to these authors, in the course of season, migration routes gradually shifted towards 
the east, and Robins migrating later covered shorter distance on the way to their wintering grounds. The studies on Robins migrating along the Baltic Sea coast (Remisiewicz 2002, Ściborska and Busse 2004) also showed temporal differentiation of birds' directional preferences - early migrants headed towards SW, while the late ones towards SE. The SE direction dominated also in 2001, was significant in 2002, and quite well-represented in 2003 - with the strongest representation in the middle part of the migration season. At the beginning of 2003 season western direction (SSW) dominated, in period $I I$ directional preferences of Robins gradually changed to the more eastern ones (SSE), but still SSW was significant. In the last period (at the end of September) SSW dominated again, but also ESE was observed. Unfortunately, there was lack of data from October, when the Robin's migration ended.

During autumn migration Robins come to the territory of Poland from three main directions: northern and north-western - from Sweden; north-eastern - from Finland, northern Russia, Estonia and Lithuania; and eastern - from Russia and Belarus (Remisiewicz et al. 1997). In the cited publication, based on ringing recoveries distribution analysis, the main wintering grounds of Robins ringed in Poland were defined, as well as four main migration routes of this species were proposed two western routes ("British" and "Atlantic"), south-western ("Alpine", which was divided into the Apennine and Mediterranean branches) and southern ("Balkan") route. Consequently, we can assume that WSW direction indicated at our ringing station leads towards the Mediterranean or Apennine wintering grounds, SSW points at the Apennines and SSE - at the Balkans. High differentiation of these preferences reflects complicated migration structure of this species. Similar pattern was observed and documented before (Ściborska and Busse 2004) at the Polish Baltic coast. Because of limited data, particularly in 2001 and 2002, directions' distributions analysed in this study should be treated with some caution. Higher number of cage tests would enlarge current knowledge on directional preferences and migration routes of Robins heading to their wintering grounds.

Different patterns of directional preferences in two species - the Chiffchaff and the Robin - are worth to note. Despite the studied periods are short and differentiated that applies to both species, the pattern observed in the Chiffchaff is clear and quite similar in different years, whilst in the Robin this pattern is complicated and difficult to interpret. Unlike in the first species, in the latter one the high intra- and interseasonal differentiation of directional preferences is observed.

Changes of directions in different parts of the season indicate that migrants from several populations pass Myscowa, however one cannot assume that each direction represents one population.

Specific conditions of orientation cage tests can influence axial behaviour of tested individuals. Stressed by the limited space of the cage, birds could show directions towards familiar environment and places well-known for them, e.g. the direction of their arrival. When migration is not disturbed, this direction is just the opposite to the one that an individual would follow while heading towards the wintering grounds. Some authors also indicated the sky visibility as a factor that influenced 
orientation behaviour of birds tested in the cages (Sandberg 1991, Ehnbom et al. 1993). One cannot exclude also genetics of migratory behaviour (Busse 1995). However, all these need more detailed studies.

\section{CONCLUSIONS}

1. Orientation cage tests are a valuable method for determination of night migrants' directional preferences.

2. Distributions of directional preferences of two species analysed in similar migration periods were different:

- In the Chiffchaff two directions dominated: SSE and WSW. Interseasonal differentiation in 2000-2003 was very low. Overall migration pattern was quite similar every year, and only some modifications caused most probably by accidental sampling and/or different weather conditions were observed.

- Robins tested in the orientation cage showed high directional differentiation. Generally, four directions were noted - SSE, SSW, ESE and WSW. The observed differentiation most probably resulted from the species different populations, which passed Myscowa.

3. To have a detailed pattern of directional distributions, the regular, representative sampling during the whole migration period is vital.

\section{ACKNOWLEDGEMENTS}

We are very grateful to the organisers of "Akcja Carpatica" that helped us to collect all data that were the basis for this study.

\section{REFERENCES}

Busse P. 1986. The problem of population differentation of birds wintering at or migrating through the Mediterranean region. Ric. Biol. Selv. 10: 53-72.

Busse P. 1992. Migratory behaviour of Blackcaps (Sylvia atricapilla) wintering in Britain and Ireland: contradictory hypotheses. Ring 14, 1-2: 51-75.

Busse P. 1995. New technique of a field study of directional preferences of night passerine migrants. Ring 17, 1-2: $97-116$.

Busse P. 2000. Bird Station Manual. Gdańsk.

Busse P., Gavrilov V.M., Ivliev V., Nowakowski J.K. 2001. Differentation of directional preferences of some nocturnal migrants on autumn migration across the central and eastern Europe. Ring 23, 1-2: 119-130.

Busse P., Marova I. 1993. Population dynamics 1961-1990 of common Leaf Warblers (Phylloscopus sp.) at some Central European bird ringing stations. Ring 15, 1-2: 61-80.

Busse P., Trocińska A. 1999. Evaluation of orientation experiment data using circular statistic doubts and pitfalls in assumptions. Ring 21, 2: 107-130.

Cramp S. (Ed.) 1988. The Birds of the Western Palearctic. Oxford. Univ. Press, Oxford - New York.

Ehnbom S., Karlsson L., Ylven R., Åkesson S. 1993. A comparison of autumn migration strategies in Robins Erithacus rubecula at coastal and an island site in southern Sweden. Ring. \& Migr. 14: 84-93.

Emlen S.T., Emlen J.T.J. 1966. A technique for recording migratory orientation of captive birds. Auk 83: 361-367. 
Formella M., Busse P. 2002. Intra-seasonal changes in directional preferences of the Reed Warbler (Acrocephalus scirpaceus) and the Sedge Warbler (A. schoenobaenus) on autumn migration at Lake Druzino (N Poland). Ring 24, 2: 15-29.

Gerrard E.C. 1981. Instinctive navigation of birds. Broadford.

Hagemeijer W.J.M., Blair M.J. 1997. The EBCC Atlas of European Breeding Birds. Their distribution and abundance. T \& A D Poyser, London.

Hedenström A., Pettersson J. 1987. Migration routes and wintering areas of Willow Warblers Phylloscopus trochilus (L.) ringed in Fennoscandia. Ornis Fenn. 64: 137-145.

Kramer G. 1949. Uber richtungstendenzen bei der nähtlichem Zugunruhe gekäftiger Vögel. In: Ornithologie als Biologische Wissenschaft. Heidelberg.

Lindström Å., Hedenström A., Pettersson J. 1996. The autumn migration of Willow Warblers Phylloscopus trochilus in Sweden: results from a nation-wide co-operative project. Ornis Svecica 6: 145-172.

Nowakowski J.K., Malecka A. 1999. Test of Busse's metod of studying directional preferences of migrating small Passeriformes. Acta orn. 34: 37-44.

Pettersson J., Lindholm G.-G. 1983. The sequential passage of different Robin Erithacus rubecula populations at Ottenby. Ornis Fenn., Suppl. 3: 34-36.

Rabøl J. 1985. The orientation of vagrant passerines on the Faroe Island, September 1984. Dansk orn. Foren. Tidesskr. 79: 133-140.

Remisiewicz M. 2002. The spatio-temporal pattern to Robin Erithacus rubecula migration: evidence from ringing recoveries. In: Both C., Piersma T. (Eds). The avian calendar: exploring biological hurdles in the annual cycle.Proc. $3^{\text {rd }}$ Conf. European Orn. Union, Groningen, August 2001. Ardea 90, 3 (special issue): 489-502.

Remisiewicz M., Baumanis J. 1996. Autumn migration of Goldcrest (Regulus regulus) at the eastern and southern Baltic coast. Ring 18, 1-2: 3-36.

Remisiewicz M., Nowakowski J. K., Busse P. 1997. Migration pattern of Robin (Erithacus rubecula) on the basis of Polish ringing recoveries. Ring 19, 1-2: 3-40.

Sandberg R. 1991. Sunset orientation of Robins Erithacus rubecula, with different fields of sky vision. Behav. Ecol. Sociobiol. 28, 77-83.

Sauer E.G.F. 1957. Die Sternorientierung nähtlich zeihender Grasmuckën (Sylvia atricapilla, borin und curruca ). Zeit. Tierpsychol. 14: 29-70.

Ściborska M., Busse P. 2004. Intra-seasonal changes in directional preferences of Robins (Erithacus rubecula) caught on autumn migration of Bukowo-Kopań ringing station (N Poland) in 1996. Ring 26, 1: $41-58$.

Trocińska A., Leivits A., Nitecki C, Shydlovsky I. 2001. Field studies of directional preferences of the Reed Warbler (Acrocephalus scirpaceus) and the Sedge Warbler (A.schoenobaenus) on autumn migration along the eastern and southern coast of the Baltic Sea and in western part of Ukraine. Ring 23, 1-2: 109-117.

Weindler P. 1997. Celestial rotation - information about an axis only? In: Orientation \& Navigation - Birds, Humans and other Animals. The Royal Institute of Navigation, Oxford.

Weindler P., Liepa V., Wiltschko W. 1998. The direction of celestial rotation affects the development of migratory orientation in pied flycatchers, Ficedula hypoleuca. Ethology 104: 905-915.

Wiltschko R., Wiltschko W. 1978. Relative importance of stars and the magnetic field for the accurancy of orientations in night-migrants birds. Oikos 30: 195-206.

Wiltschko R., Wiltschko W. 2001. Avian navigation from historical to modern concepts. Animal behaviour 65: 257-272. 